\title{
TRADUÇÃO COMO CONSTRUÇÃO DE CONHECIMENTO: EXPERIÊNCIAS NA UNIVERSIDADE DE BRASÍLIA
}

\author{
Ana Helena Rossi ${ }^{1}$
}

\begin{abstract}
Resumo: Tradução é um processo que compreende distintas etapas interligadas entre si por questóes epistemológicas referentes à construção do saber. Quando se traduz, existem sempre os lócus A e B, espaços epistemológicos sobre os quais o/a tradutor(a) intervém pela linguagem, a começar pelo lócus A (texto de partida) até operacionalizar as metamorfoses do texto que váo desabrochar no lócus $\mathrm{B}$ (texto de chegada). Tradução tem a ver com conhecimento, e como esse conhecimento se organiza em um polo para ser modificado no outro polo. Daí a importância de termos um percurso analítico (Antoine Berman), e entendermos a importância do continuum de conversóes, conceito cunhado por Marcos Vinícius Leite a partir da leitura do texto de Walter Benjamin, "A tarefa do tradutor" [Die Aufgabe des Übersetzers], e desenvolvido por mim na Universidade de Brasília. A metodologia acima propóe dois produtos: de um lado, o texto traduzido e, do outro lado, o discurso sobre a traduçáo que remete à epistemologia do saber.
\end{abstract}

Palavras-chave: Tradução. Epistemologia do saber. Linguagem. Antoine Berman. Walter Benjamin.

\section{TRANSLATION AS CONSTRUCTION OF KNOWLEDGE: EXPERIENCES AT THE UNIVERSITY OF BRASÍLIA}

\begin{abstract}
Translation is a process that envolves many steps linked by epistemological questions in relation with knowledge construction. When ones translates, there is always two loci, $\mathrm{A}$ and $\mathrm{B}$, where the translator intervene in the language. This process starts by locus A (source texte) until make operationnel textuels metamorphosis that produces locus B (target texte). Translation have connections with knowledge and how this knowledge organizes itself in one locus in order to be reconstruct in the other one. That's why it's important to have an analytical path (Antoine Berman) in order to understand the importance of conversion continuum, concept structured by Marcos Vinicius Leite from the lecture of Walter Benjamin's text "The task of the translator" [Die Aufgabe des Übersetzers], and developed by me in the Universidade de Brasília. The methodology above gets two products: in one side, the translated texte, and on the other, the discourse about translation that refers to the epistemology of knowledge.
\end{abstract}

Keywords: Translation, Epistemology of knowledge, language, Antoine Berman, Walter Benjamin.

1 Atua no Departamento de Línguas Estrangeiras e Tradução (LET) do Instituto de Letras da Universidade de Brasília, e nos Programas POSTRAD e POSLIT da Universidade de Brasília. 


\section{Introduçáo}

O objeto deste artigo refere-se à relação entre a tradução e a epistemologia do saber e suas epistemes, que cobrem os campos conceitual e metodológico que quero delimitar aqui. Trata-se de um diálogo que desenvolvo há vários anos no âmbito acadêmico, na Universidade de Brasília, e que relaciona tradução e saber, ou melhor dizendo, como o saber é construído no âmbito da tradução, como ele se operacionaliza, quais as suas finalidades, qual é a metodologia possível para identificá-lo, observar a episteme em jogo. Então, inicialmente, vejamos algumas definições que servirão de embasamento para a nossa discussão.

Por tradução, apoio-me no que construí na Universidade de Brasília durante todos os meus anos de ensino e de orientação de trabalhos acadêmicos em sala de aula, e que está objetivado nos trabalhos de graduação e de pós-graduação. Tradução é processo ${ }^{2}$ que se define como um conjunto de atos cuja inteligibilidade pautase por um(a) metodologia/sistematização/percurso analítico que correlaciona as atividades realizadas em distintos momentos " $\mathrm{t}$ " da tradução. Tais atividades não são independentes entre si, pois elas se redefinem umas em relação às outras dentro de um universo que cita e correlaciona elementos dependentes do processo tradutório, e cuja base é o recorte da realidade definida pelo texto a ser traduzido.

Tradução consiste em selecionar, adequar, organizar, (re)organizar, estabelecer pontes, critérios, diferenças de percepção, imaginação, elaborar cortes, e sustentar posições, pois, segundo Gaston Bachelard ${ }^{3}$ trata-se de conceber/imaginar/sonhar o que está sendo traduzido, e conceber o ponto fulcral do texto que será traduzido. Isto relaciona-se à capacidade de interpretar categorias presentes no texto. Estas imaginação e criatividade embasam o ato de tradução porque traduzir é criar e processar, e interpretar, e selecionar, e adequar, como também organizar. Tradução é, pois, uma organização de elementos que identificam e sistematizam os saberes em jogo, reconhecendo-os como tal no lócus A (texto de partida) para reconstruílos lócus B. Onde está esse conhecimento? No texto a ser traduzido, que é sempre o resultado de uma cultura, de uma cosmovisão, de uma opção científica fruto de hipóteses específicas, de uma poesia que re-elabora o recorte do mundo. A ressignificação constitui uma etapa fundamental no trabalho de tradução. Não é possível traduzir, no sentido que operacionalizo aqui, sem uma compreensão fina a priori do material a ser traduzido, pois trata-se de recombinar/redistribuir/ reinventar os diferentes elementos em jogo. Tradução tem a ver com linguagem ${ }^{4}$, pois relaciona-se com a nomeação das coisas do mundo. A nossa compreensão (das

2 Autor. "Processos e experiências: pensando a tradução". caleidoscópio: linguagem e tradução. Vol, 2. n. 1. Junho de 2018. p.1-14

3 BACHELARD, Gaston. L'eau et les rêves: essai sur l'imagination de la matière. Paris. Librairie José Corti, 1942, 267 pp.

4 ROSCOE-BESSA, Cristiane. "O conceito de linguagem em Walter Benjamin e sua relação com a tradução”. Traduzires. Vol. 4. 2013. p. 29-39. 
coisas, do mundo, e de nós mesmos) provém da linguagem, do elemento linguístico que nos faz constituir as categorias de inteligibilidade. São estas operações que constroem o sentido (ou não) daquilo que traduzimos.

Outro conceito que trago aqui é o de episteme, no sentido desenvolvido por Michel Foucault em seu livro Les mots et les choses ${ }^{5}$, e de maneira mais indireta em Archéologie du savoir com a noção de "discurso" e de "discursividade", levando em conta as muitas críticas já tecidas a este conceito, cujas definições retomo aqui ${ }^{7} \mathrm{Na}$ entrevista de Michel Foucault com Noam Chomsky (1971), epistemologia é:

identificar as transformações de um saber no interior ao mesmo tempo do campo geral das ciências, como também, no interior do campo de alguma maneira vertical que constitui uma sociedade, uma cultura, uma civilização em um dado momento. ${ }^{8}$ (tradução e grifos meus)

O elemento fundamental aqui são as transformações do saber enquanto conhecimento do mundo, estabelecido a partir de uma dupla identificação no campo geral das ciências, saber esse que estabelece distinções importantes no processo tradutório. Em Les mots et les choses, Michel Foucault confirma que:

Não se trata de conhecimentos descritos em seu progresso rumo a uma objetividade na qual a ciência de hoje poderia, enfim, se reconhecer; o que gostaríamos de trazer à luz do dia é o campo epistemológico, a episteme na qual os conhecimentos, considerados fora de todo e qualquer critério que se refira a seu valor racional ou a suas formas objetivas, confirmam sua positividade e manifestam assim uma história que não é aquela de sua perfeição constante, mas, sim, aquela de suas condições de possibilidade. ' (Tradução e grifos meus)

$\mathrm{Na}$ tradução, as condições de possibilidade são aquelas necessárias para que haja conhecimento. É muito difícil registrar esse fazer tradutório, cuja característica é ser volúvel, estar em andamento, além de trazer idiossincrasias que se relacionam

5 FOUCAULT, Michel. Les mots et les choses: une archéologie des sciences humaines. Paris. Gallimard. 1966, 400p.

6 FOUCAULT, Michel. L’Archéologie du savoir. Paris. Gallimard. 1969. 175p.

7 JUIGNET, Patrick. Michel Foucault et le concept d'épistème". In: Philosophie Science et société (en ligne). 2015. https://philososciences.com/philosophie-generale/la-philosophie-etsa-critique/10-michel-foucault-episteme (/philosophie-et-societe/29-philosophie-generale/-laphilosophie-et-sa-critique/10-michel-foucault-episteme). Acesso em 01/11/2018

8 Original em francês: "saisir les transformations d'un savoir á l'intérieur à la fois du domaine généal des sciences et, également, à l'intérieur du domaine en quelque sorte vertical que constitue une société, une culture, une civilisation à un moment donné."

9 Original em francês: "Il ne sera pas question de connaissances décrites dans leur progrès vers une objectivité dans laquelle notre science d'aujourd'bui pourrait enfin se reconnaître; ce qu'on voudrait mettre au jour, c'est le champ épistémologique, l'épistèmè où les connaissances envisagées hors de tout critère se référant à leur valeur rationnelle ou à leurs formes objectives, enfoncent leur positivité et manifestent ainsi une bistoire qui n'est pas celle de leurperfection croissante, mais plutôt celle de leurs conditions de possibilité." 
com as escolhas feitas pelo tradutor, e não apenas com o resultado final do texto. Trata-se das condições histórico-sociais-culturais de existência do texto. Assim, tornar possível uma tradução significa registrar o que foi possível fazer nos distintos momentos " $t$ " do processo. Assim, episteme pode ser definida como a ordem/a organização que estrutura a linguagem em um determinado tempo histórico levando em conta as condições de sua possibilidade, que precisam ser registradas para serem analisadas enquanto conjunto de decisões tomadas. Pois, o que está em jogo é construção/identificação do saber, isto é, "uma obra enraizada na biografia de sua experiência." 10 A experiência chama as possibilidades de compreensão do que é feito, como afirmou Paracelso a respeito de "experiência", assim como sua importância na historiografia das ciências:

Ele sustentava que apenas a experiência, e não a aprendizagem nos livros permitiria realmente saber curar. Trazendo uma perspectiva alquímica ao estudo da vida e da medicina, Paracelso participou da unificação das ciências. ${ }^{11}$ (Tradução e Grifos meus)

Nesse sentido, a experiência do tradutor constitui o fio diretor do processo tradutório, pois, a partir da mesma o tradutor toma decisões, decide o que manter e o que retirar da tradução. A tradução configura-se assim primeiramente como um processo, e em segundo lugar, como um lugar epistemológico, onde categorias são reformuladas/reorganizadas com vistas a obter um outro texto compreensível.

\section{Tradução como processo epistemológico}

Esta pesquisa inicia-se a partir da minha atuação como tradutora, e toma corpo no âmbito da minha atuação na Universidade de Brasília, desde março de 2011, como professora no Departamento de Línguas Estrangeiras e Tradução do Instituto de Letras da UnB, atuando em sala de aula, orientando monografias de fim de curso (TCC), dissertações de Mestrado, realizando cursos de extensão na Universidade de Brasília. Iniciei esse trabalho na Universidade com textos historicamente datados, todos publicados em editoras, portanto facilmente identificáveis. Os gêneros textuais também foram os mais diversos: romances, poesia, artigos científicos de várias áreas do conhecimento, manuais de empresa, contos, estórias infantis, textos históricos, textos jurídicos.

Durante esses anos, desenvolvi uma metodologia na área da tradução para orientar os alunos. O primeiro passo da metodologia era a escolha de textos que eram validados por mim. Surge a primeira dificuldade condizente com todo

10 KRISTEVA, Julia. Le génie féminin 1. Hannah Arendt. Paris. Fayard. 1999. p. 9. Traduzido por mim a partir do original a seguir: “(...) une oeuvre enracinée dans la biographie de leur expérience."

11 Traduzido do original por mim, a seguir: 'Il soutenait que seule l'expérience, et non l'apprentissage dans les livres, permettait véritablement de savoir soigner. En apportant une perspective alchmique à l'étude de la vie et de la médecine, Paracelse a participé à l'unification des sciences". in: Richard Aline, Le Meur Hélène. Les grandes controverses scientifiques. Paris. Dunod. 2014, pp. 2-5. 
trabalho tradutório: o que significa ler um texto. Esta etapa que inicia o processo, etapa da escolha do texto confirmou empiricamente que a leitura realizada pelo tradutor remete a competências dos alunos de tipo linguístico-cultural e social que lhes proporcionam as condições para identificar o conteúdo de um texto, sua intertextualidade, que saem da opinião oriunda do senso comum "eu acho que...". São questionamentos que orientam os alunos a identificarem o formato do texto, sua escrita, sua historicidade, além da sistematização interna. Com o passar dos anos, minha atenção voltou-se progressivamente mais para textos literários que, na minha visão, contém um conjunto de problemas existentes também nos demais gêneros textuais. Para mim, os textos literários são os mais complexos e os mais difíceis para a tradução, pois, estabelecem uma relação complexa entre o que é real, o que é verossímil, o que é verdadeiro e o que é falso, o que é histórico, o que é sociológico, categorias essas que os demais textos assumem como definitivas, e que os textos literários problematizam. Por outro lado, a plasticidade do texto literário é observada em suas múltiplas utilizações: eles podem ser o testemunho de uma época, dizendo, às vezes, a depender da pluma do/a autor(a), mais sobre o real do que um texto classificado como histórico ou sociológico. Observamos também sua utilização no âmbito histórico/sociológico/antropológico de maneira complementar ao texto histórico. Em suma, o conhecimento sobre o mundo se encontra registrado na linguagem dos textos literários.

\subsection{Iniciando o processo tradutório}

O início do processo tradutório dá-se com a escolha do texto, e com a explicitação dos critérios por parte dos alunos. Seguem, abaixo, os critérios que foram introduzidos em sala de aula.

1. O texto a ser escolhido deve ser um texto clássico, conhecido, datado e com uma história.

2. O texto deve ter sido publicado por uma editora/site/arquivo identificáveis como prova de sua existência.

3. Não são aceitos textos de própria autoria.

4. Deve ser escrita uma justificativa, isto é, identificar o conjunto de leis internas que regem esses textos. A justificativa é um texto redigido e formalizado com parágrafos estruturalmente coerentes entre si. Essa demanda trouxe a primeira grande dificuldade para os alunos: o que é justificar o texto? Como estruturar um parágrafo? O que é um parágrafo?

Com essa etapa, objetiva-se dar ferramentas aos alunos para identificar a estrutura do texto, suas leis de coesão e de coerência. Cada uma das dificuldades foi sistematizada como um problema que devia ter uma resposta. Do ponto de vista pedagógico, a interação com os alunos foi fundamental para formalizar tais critérios. Aprimorei a metodologia semestre após semestre, orientação após orientação, monografia de curso após monografia de curso. Sou-lhes muito grata. 
Paralelamente, a escolha do par linguístico precisava ser melhor compreendida, e deixar de ser óbvia. Na disciplina Teoria da Tradução 2 - disciplina obrigatória do curso de Letras - Tradução do Departamento de Línguas Estrangeiras e Tradução, conjuntamente com as disciplinas de versão (dadas em francês) intituladas de "Práticas de Tradução - Textos Literários - português-francês", e "Práticas de Tradução - Textos Gerais - português-francês", e "Práticas de Tradução - Textos Técnico-Científicos - português-francês", orientei trabalhos que utilizaram os três pares linguísticos em estudo na Universidade no curso de Letras-Tradução, tanto em trabalhos de tradução quanto de versão: português-francês/francês-português, português-inglês/inglês-português, espanhol-português/português-espanhol.

A escolha do par linguístico deve ser problematizada no âmbito do processo tradutório. Não é a mesma coisa fazer uma versão e fazer uma tradução. Os dois locus (texto de partida e texto de chegada) devem ser problematizados em relação ao seu lugar de estranhamento. Quando se opta por uma tradução, operacionalizase esse processo dentro de um movimento que parte do locus desconhecido para o conhecido, aquele conhecido como "língua materna". A versão, outrossim, parte do lócus conhecido em direção ao desconhecido. Tais orientações tradutórias proporcionam dificuldades muito distintas aos alunos e para todo aquele que traduz.

Nas minhas experiências em sala de aula, a maioria dos alunos da graduação iniciava o semestre com a ideia firme e forte que eles iam "passar" o texto de uma língua para outra, não importando se era tradução ou versão. Nessa lógica, o que existia no texto A (texto de partida) existiria também o texto B (texto de chegada), embora isto fosse afirmado sem muita compreensão. Vários pressupostos embasavam essa crença acerca da tradução. Um deles é que as línguas funcionavam de maneira simétrica. Era só "passar" de uma língua para a outra com a ajuda dos dicionários na busca de palavras desconectadas do seu contexto textual. Posso dizer que essa crença acerca do que é tradução está muito presente nos alunos e é mais comum do que se pensa. Nesta visão, a tradução consiste em um ato de "passagem" que nunca é problematizado. Desconsiderava-se, portanto, o recorte semântico, visual, sonoro (verbivocovisual, segundo a poesia concretista) do léxico, a etimologia da palavra, e tudo o que que torna um texto único.

A língua é um corpo social, ativado pelo coletivo, e aprendida com ele e nele. É o que chamamos de socialização. Se somos seres falantes de língua(s), é porque fomos socializados na prima infância, assim como posteriormente, para falar a(s) línguas, para moldar a nossa garganta e falar sem sotaque, durante anos de aprendizado até chegarmos ao que parece óbvio. Mas isso nós já esquecemos. Essa proposta de tradução nos faz adentrar novamente nesses terrenos complicados da nossa experiência linguística individual, da história dessa experiência. Lembro-me o meu perfeito estranhamento quando aprendi, aos 10 anos de idade, na Bélgica, onde morava com a minha família, que a língua flamenga possui um "neutro", e que o particípio passado era colocado no final da frase. Isso teve uma série de consequências na minha compreensão do que é tradução. Esse estranhamento orientou-me para as idiossincrasias das línguas, suas sobrevivências, suas dimensões 
nunca imaginadas em outra língua. Porque língua é cultura, e organização de conhecimento, como afirma Aryon Rodrigues:

Se a gente entende linguística como o estudo específico da natureza da linguagem humana e as suas múltiplas manifestações nas línguas dos povos, a primeira relação é justamente esse ponto comum, a capacidade humana de comunicação através das línguas, e não apenas comunicação, mas organização do conhecimento. Não é só saber dar recado para o outro. É entender as coisas. ${ }^{12}$ (Grifos meus)

Trata-se da "língua-cultura", que são inteligibilidades culturais organizadas na linguagem de um povo a respeito do mundo, e que o tradutor identifica:

Se ele domina as duas línguas, quando há desencontro de concepções básicas, o que ele faz é simplesmente descrever na língua que ele está usando, para a qual ele está traduzindo, uma tradução mais ou menos literal do que os outros dizem, e aí ele tem que interpretar um pouco, dizer como eles estão entendendo aquilo que é diferente do que ele mesmo aprendeu. Ele tem que estar com o pé nos dois lados, do lado da língua do outro, e da língua dele para a qual ele está traduzindo. ${ }^{13}$ (Grifos meus)

Assim, cada língua constitui-se em um locus onde imperam concepções básicas com suas idiossincrasias, sua história.

\subsection{Registrar o processo de traduçáo: a traduçáo é locus da pesquisa}

O processo tradutório é tudo, menos linear. Ele tem seus vai-e-vem, e é constituído por categorias que dialogam entre si. Em razão da complexidade da tarefa tradutória, a questão inicial é o registro do que está sendo elaborado com vistas a identificar a historicidade das soluções, seus erros e acertos. Sem esse registro que assume formas como um diário ou um comentário da tradução, o paratexto constituído no decorrer do trabalho tradutório desaparece. Sem memória do processo tradutório, impossível questioná-lo, rever as escolhas tradutórias inquirindo-as à luz do que foi feito. Impossível ter um movimento re-flexivo, no sentido da etimologia:

Do latim tardio reflexio, -onis, volta, regresso, reflexão. Substantivo feminino. Ato ou efeito de refletir. 2. Prudência. 3. Meditação. 4. Argumento; objeção. ${ }^{14}$

"Reflexivo consiste, pois, em uma "flexão" novamente. Assim, um tradutor reflexivo está em constante movimento para flexionar, mais uma vez, em direção ao texto original, retomando as versões anteriores, reler de novo a primeira versão,

12 Autor. "Entrevista com o Prof. Dr. Emérito Aryon Dall'Igna Rodrigues por Autor, Traduzires, n. 2, Dezembro de 2012, p. 127.

13 Autor, "Entrevista com o Prof. Dr. Emérito Aryon Dall'Igna Rodrigues por Autor, op. cit., p. 130.

14 Dicionário PRIBERAM, https://dicionario.priberam.org/reflex\%C3\%A3o. Acesso em 01 de novembro de 2018. 
a segunda, a terceira para compreender as escolhas tradutórias realizadas nas diferentes versões, a fim de produzir um conhecimento sobre a tradução. Nesse tipo de percurso metodológico, alcançam-se dois resultados: (1) o texto traduzido, e (2) o material crítico/discurso sobre a tradução que é também um conhecimento pertencente à tradução. Assim fazendo, o tradutor torna-se pesquisador da tradução na medida em que produz dados a partir das pesquisas realizadas, organizouos, sistematizou-os, analisou-os e interpretou-os. Foi fundamental nesta etapa do processo tradutório, o conceito de continuum de conversões cunhado por Marcos Vinícius Leite ${ }^{15}$ a partir da leitura de Walter Benjamin, e desenvolvido por mim no âmbito de trabalhos acadêmicos. Entende-se, por continum de conversões, os infinitos estados do texto no decorrer da tradução. Trata-se de cada uma das versões/traduções obtidas a partir desse percurso analítico, com suas idiossincrasias, suas decisões. Esse conceito explicita uma das características fundamentais da linguagem que é a sua infinita plasticidade. Portanto, o conceito estabelece uma relação entre os diferentes estados de concretude do texto - suas diferentes versões ou traduções - que podem ser organizados em termos temporais, estabelecendo a cronologia do processo de tradução. $\mathrm{O}$ continuum de conversões identifica o processo tradutório. Registrando suas etapas, analisando-as, não como partes separadas e independentes umas das outras, mas como partes de um todo que se inicia no lócus A e termina, sempre provisoriamente, no lócus $\mathrm{B}$, eu (tradutor/a), tenho a dimensão macro e a micro conjugadas. Entre o lócus A e o lócus $\mathrm{B}$ identifica-se o processo. Em seu ensaio intitulado "A tarefa do tradutor", Walter Benjamin formula que o tradutor tem uma tarefa. Nesse entendimento, o tradutor tem uma tarefa que é realizar um conjunto de tarefas - intituladas de "tradução" - que vão construir a tradução. Tais conjuntos de tarefa, caso não sejam registradas são perdidas, e aí perdem-se os elos inteligíveis entre as atividades do processo tradutório, que darão suporte à inteligibilidade da tradução. $\mathrm{O}$ registro desse processo permite constituir dados para a pesquisa sobre a tradução. Sabendo que toda pesquisa responde a um corpo de teorias, hipóteses, problematizações, resultados, análise dos dados, validação e, construção de novas hipóteses, é de fundamental importância inserir a tradução no locus da pesquisa, validando progressivamente as hipóteses.

No decorrer da elaboração das versões e das traduções iniciam-se os quadros. Existem distintos quadros de vários tipos cujo principal é o quadro matriz. Esse quadro contém todas as versões ou traduções do texto. A matriz é de onde se origina toda a pesquisa. É preciso ordená-la para dar início ao processo tradutório com a primeira versão ou tradução, e os respectivos comentários que se desprendem das escolhas tradutórias. A matriz não pode ser alterada, nem apagada a fim de manter as escolhas tradutórias da maneira mais fidedigna possível. A análise desse quadro matriz consolida a leitura realizada pelo tradutor do texto do locus A, com todas as suas idiossincrasias explicitadas. A matriz identifica, no sentido benjaminiano, a tarefa do tradutor, que é a experiência de estranhamento e de estranheza. Em

15 LEITE, Marcos Vinícius. "A estrutura da linguagem em Walter Benjamin". Revista Ética e Filosofia Política. No 12. Volume 1. Abril de 2010. p. 11-23. 
paralelo, o tradutor mantém um diário de tradução. A primeira versão ou tradução traz à tona um tipo de conhecimento sobre :

1. as características da linguagem do texto de partida - lócus A - (estruturas sintáticas, léxicos, campos lexicais, expressões idiomáticas, temas, etc.);

2. o que deve ser estar estruturado no texto de chegada - lócus B - (estruturas sintáticas, léxicos, campos lexicais, expressões idiomáticas, temas, etc.);

3. a relação que une os dois textos, de suas leis de funcionamento - lócus A e -B;

4. o desconhecimento do tradutor ; e o que deve ser feito para ultrapassá-las;

5. o que está sendo construído na tradução a partir das escolhas tradutórias, e que eu chamo de projeto de tradução. É o "confronto do/a tradutor(a) consigo mesmo(a), e não apenas com a imagem que ele/ela tem de si."

Trata-se de um dos momentos cruciais no processo, momento em que a tradução é experimentada enquanto tradução, enquanto tradutor(a) pela apropriação do texto e dos inúmeros problemas que norteá-lo-ão até sua formatação final. Os meus alunos qualificaram esse etapa inicial com vários nomes: "monstrengo", "sem forma", "não entendo". Muitas vezes, o choque era tão grande que eles não conseguiam dizer nada a respeito. A surpresa visível em seus olhos porque essa etapa desconstruía duradouramente a imagem que eles tinham de si próprios como tradutores. A impossibilidade de assumir que o "monstrengo" não havia sido produzido por eles mesmos. Esse estranhamento a respeito do que sai das nossas mãos é um poderoso choque para entendermos o que está em jogo quando nos experimentamos como tradutor. Trata-se de um processo que inclui também a sua dinâmica de subjetividade com a qual temos que lidar, e que incide na pesquisa. O objetivo é sistematizar essa subjetividade para entender para onde estamos caminhando, isto é, qual é o projeto de tradução que está sendo gerado.

O projeto de tradução é a articulação progressiva por parte do tradutor entre a intenção da tradução e sua realização concreta. É a construção entre pensar a tradução idealmente e sua construção progressiva sob a forma de um discurso coerente e coeso. O projeto de tradução traz à luz o que e como o tradutor traduz, suas escolhas tradutórias. Isto permite que as categorias analíticas sejam expostas. Esse olhar descontrói o conhecimento presente no lócus A reconstruindo-o no lócus B. As categorias identificam distintos conceitos que tem a ver com o tema do texto a ser traduzido. Várias questões afloram aos poucos. Elas são revistas nas versões e traduções subsequentes (a versão 2 , a versão 3 , a versão 4 , a versão “n”) do quadro matriz. Nesse processo de realizar as versões, as dúvidas aparecem de maneira organizada.

\subsection{O conhecimento pela traduçáo da letra: "traduzir em"}

No processo de tradução, as categorias analíticas são portadoras de sentido que se expressam por intermédio da letra, conceito presente em distintos autores, e em várias disciplinas. O antropólogo e tradutor francês, Pierre Clastres, apresenta 
em seu livre Le grand parler: Mythes et chants sacrés des Indiens Guarani ${ }^{16}$, uma tradução dos mitos e dos cantos sagrados dos Índios Guarani coletados pelo antropólogo paraguaio Leon Cadogan. Como ele diz, existe uma tensão com a letra, que remete ao trabalho árduo da tradução:

“Traduzir é, claro, tentar passar para um universo cultural e linguístico determinado, a letra e o espírito de textos oriundos de um sistema cultural diferente, produzidos por um pensamento próprio. Quando, como nos mitos, o texto é uma narração de aventura, a tradução não levanta muitos problemas. O espírito cola à letra, a enigma é mais ou menos excluída da narração. Mais árduo, e por isso sem dúvida mais apaixonante foi o trabalho de traduzir textos religiosos. (...) Posição, então, deliberadamente assumida: preocupados em nos distanciarmos o menos possível da letra do texto, nós tentamos, por isso mesmo, restituir o espírito, estimando, para parafrasear uma famosa afirmação que, traduzir os Guarani, é traduzi-los em guarani. Tradução quase sempre literal, portanto (...) Fidelidade à letra em vista de preservar o espírito, e talvez, no que diz respeito a certos fragmentos, uma aparência de escuridão."17 (Tradução e grifos meus)

Pierre Clastres define na citação acima a tradução como sendo "traduzir os Guarani [... significa] traduzi[ndo-os] em guarani ${ }^{18 " . ~ A ~ p a r t i ́ c u l a ~ " e m " ~ o p e r a c i o n a l i z a ~}$ a tradução no âmbito da locus A, e restitui essas mesmas categorias no locus $\mathrm{B}$. O certo e o inteligível, quando reposicionados, tornam-se o incerto que deve ser reorganizado para se tornar inteligível. A tarefa do tradutor consiste em organizar o processo de tradução no âmbito de uma visão macro que influi sobre a letra, para reconstruí-la e alcançar uma inteligibilidade que é o projeto de tradução.

Outro autor que utiliza o conceito de "letra" é Antoine Berman, tradutor e teórico francês. Em seus livros ${ }^{19}$, a letra é o que está escrito, da forma como está escrito. Falando também a partir da sua experiência como tradutor de romances de

16 CLASTRES, Pierre. Le grand parler: Mythes et chants sacrés des Indiens Guarani. Paris. Seuil. 1974. 140 p.

17 CLASTRES, Pierre. Le grand parler: Mythes et chants sacrés des Indiens Guarani. Paris. Seuil. 1974. 14-15p. [Original: "Traduire est, bien sûr, tenter de faire passer dans un univers culturel et linguistique déterminé, la lettre et l'esprit de textes issus d'un système culturel différent, produits par une pensée propre. Lorsque, comme dans les mythes, le texte est une narration d'aventures, la traduction ne pose guère de problèmes. L'esprit colle à la lettre, l'énigme est à peu près exclue du récit. Plus ardu, et pour cela sans doute passionnant fut le travail de traduction des textes religieux. (...) Parti pris donc délibéré que le nôtre: soucieux de nous écarter le moins possible de la lettre du texte, nous avons par là même essayé d'en restituer l'esprit, estimant, pour paraphraser une affirmation fameuse, que traduire les Guarani, c'est les traduire en guarani. Traduction presque toujours littérale, par conséquent (...). Fidélité à la lettre en vue d'en conserver l'esprit, et peut-être, pour certains fragments, une apparence d'obscurité."]

18 Trata-se da questão central que é "traduzir em" significa introduzir no âmbito da tradução o recorte conceitual do locus A refletindo sobre como organizá-los no locus B.

19 BERMAN, Antoine. A tradução e a letra, ou o albergue do longínquo [La traduction et la lettre ou l'auberge du lointain]. [tradutores Marie-Héléne Catherine Torres, Mauri Furlan, Andréa Guerini], NUPLITT/7Letras. Rio de Janeiro; BERMAN Antoine. Pour une critique des traductions: John Donne. Paris, Gallimard. 1995. 275p. 
autores latino-americanos para a língua francesa, ele confirma que é preciso traduzir o que está escrito, da maneira como está escrito ("a letra"). A convergência desses dois autores reside no fato de que a "letra" é o que se escreve, como se escreve, podendo se desdobrar em distintas questões pertinentes referentes ao processo tradutório.

\title{
Conclusão provisória
}

A tradução se estrutura sob a forma de um processo que dá acesso a uma compreensão do processo tradutório. À medida em que o tradutor experimenta a linguagem, posicionada de maneira tensa no locus A e no locus B, o processo se estrutura. Esta postura tanto metodológica quanto teórica auxilia o tradutor, provendo-lhe um olhar sistêmico sobre a tradução de maneira a produzir um discurso sobre o que é traduzido, retirando-lhe da posição de falar da sua tradução a partir de elementos esparsos e sempre fragmentados. Como observa Antoine Berman:

\begin{abstract}
Os tradutores geralmente não gostam muito de falar de "teoria". Consideramse como intuitivos e artesãos. Entretanto, desde o início da tradição ocidental, a atividade tradutória é acompanhada de um discurso-sobre-a-tradução. Assim, temos ao longo dos séculos (citando apenas os nomes mais conhecidos), os textos de Cícero, São Jerônimo, Frei Luís de Leon Lutero, Du Bellay, Dolet, Rivarol, Herder, Humboldt, A. W. Schlegel, Goethe, Schleiermacher, Chateaubriand, Pouchkine, Valéry, Benjamin, Pound, Armand Robin, Borges, Bonnefoy, Octavio Paz etc. Esse discurso é essencialmente dos tradutores, mesmo que se duplique, em cada época, por aqueles dos não tradutores, que não fazem mais do que refleti-lo e repeti-lo. Eu o chamo de "discurso tradicional". Ele é tradicional em dois sentidos. Primeiramente, vem do fundo da tradição da cultura ocidental. Depois, pertence a um mundo no qual a tradução é considerada como um dos pilares do próprio caráter da tradição, ou seja, do modo de ser dos homens. Traduzione tradizione, dizem os italianos; unindo passado e presente, próximo e distante, a tradução semeia a cultura, ela mesma experimentada como um conjunto de tradições. ${ }^{20}$
\end{abstract}

A capacidade de produzir um discurso orgânico sobre a tradução, como diz Antoine Berman, relaciona-se com a possibilidade, por parte do tradutor, em identificar a lógica das transformações textuais a que o texto situado no locus A foi submetido. $\mathrm{O}$ tradutor operacionaliza o seu modus operandi por intermédio da transformação da linguagem, ao deslocar categorias analíticas, e tendo a consciência, cada vez maior, de que cada língua tem uma visão do mundo, e expressa essa visão na linguagem.

A tradução é, pois, um fenômeno de reorganização conceitual atuando em dois lócus que tem relações de vai-e-vem: o lócus A ("texto de origem") que o tradutor acessa, transforma e reelabora, e o lócus B do "texto de chegada" que o tradutor

20 BERMAN, Antoine. "A tradução e seus discursos”. Alea. Volume 11. número 2. Julho-Dezembro de 2009. p. 341-353 
re-estrutura a partir do locus A. O processo de inteligibilidade levado a cabo pelo tradutor coloca em evidência que esse "passar" de uma língua para outra não é um procedimento de ordem mecânica, mas é analítico e de conhecimento. A teoria benjaminiana da linguagem confirma que a tradução ${ }^{21}$, sendo operacionalizada na linguagem, tem a ver com a natureza da linguagem humana, tal como o ser humano utiliza essa mesma linguagem que é o ato de nomear as $\operatorname{coisas}^{22}$ :

(...) Portanto, a essência linguística do homem está no fato de ele nomear as coisas. (...) Para quê nomear? A quem se comunica o homem? - Mas será essa questão, no caso do homem, diversa da de outras formas de comunicação (linguagens)? (...) Antes de responder a esta pergunta, deve-se examinar novamente a questão: como se comunica o homem? Deve-se estabelecer uma diferença clara, colocar uma alternativa diante da qual, seguramente, uma concepção da linguagem essencialmente falsa seja desmascarada. Será que o homem comunica a sua essência espiritual através dos nomes que ele dá às coisas? Ou nos nomes? (...) Por sua vez, pode aceitar apenas que comunica alguma coisa a outros homens, pois isso se dá através da palavra com a qual eu designo uma coisa. Tal visão é a concepção burguesa da linguagem, cuja inconsistência e vacuidade devem resultar cada vez mais claras, a partir das reflexões que faremos a seguir. Esta visão afirma que o meio [Mittel] da comunicação é a palavra; seu objeto: a coisa; seu destinatário, um ser humano. Já a outra concepção não conhece nem meio, nem objeto, nem destinatário da comunicação. ${ }^{23}$

Exclui-se a importância da/o "coisa/objeto" para focar no que a/o "coisa/ objeto" transporta e diz de si mesmo no âmbito da linguagem. Assim, traduzir remete a concepções do mundo que, em contato umas com as outras, devem ser elucidadas a partir das categorias de conhecimento que as compõem e que estão presentes na cultura. O tradutor não é um "passante" de uma língua para outra. Ele é aquele que se mantém tanto lá quanto cá, e percebe o quão fundamental torna-se a sua própria formação enquanto profissional para compreender as categorias em jogo, e restituí-las em outro lócus, preservando a inteligibilidade para não jogar fora o bebê com a água do banho.

21 BENJAMIN, Walter. "A tarefa-renúncia do tradutor" [trad. Susana Kampff-Lages]. in Castello Branco, Lúcia (org.). A tarefa do tradutor, de Walter Benjamin - quatro traduções para o português. Belo Horizonte. Fala/UFMG, 2008, p. 66-81.

22 RAULET, Gérard. "L'atelier du traducteur. Benjamin et les Tableaux parisiens". Revue italienne d'études françaises [online]. 4. 2014, http://journals.openedition.org/rief/656. Acesso em 30 de agosto de 2018.

23 BENJAMIN, Walter. "Sobre a linguagem em geral e sobre a linguagem do homem" in Escritos sobre mito e linguagem (1915-1921), [Organização, apresentação e notas Jeanne Marie Gagnebin; Tradução Susana Kampff Lages e Ernani Chaves], São Paulo: Livraria Duas Cidades/34 editora, 2011, p. 55. 


\section{Referências}

BACHELARD, Gaston. L'eau et les rêves: essai sur l'imagination de la matière. Paris : Librairie José Corti, 1942, 267 pp.

BENJAMIN, Walter. “A tarefa-renúncia do tradutor” [trad. Susana Kampff-Lages], in Castello Branco, Lúcia (org.), A tarefa do tradutor, de Walter Benjamin - quatro traduções para o português, Belo Horizonte: Fala/UFMG, 2008, p. 66-81.

"Sobre a linguagem em geral e sobre a linguagem do homem" in Escritos sobre mito e linguagem (1915-1921), [Organização, apresentação e notas Jeanne Marie Gagnebin; Tradução Susana Kampff Lages e Ernani Chaves], São Paulo: Livraria Duas Cidades/34 editora, 2011, p. 55.

BERMAN, Antoine. A tradução e a letra, ou o albergue do longínquo [La traduction et la lettre ou l'auberge du lointain], [tradutores Marie-Héléne Catherine Torres, Mauri Furlan, Andréa Guerini], NUPLITT/7Letras, Rio de Janeiro; 2009, p. 341-353 . "A tradução e seus discursos", Alea, Volume 11, número 2, Julho-Dezembro de Pour une critique des traductions: John Donne, Paris, Gallimard, 1995, 275p.

CHEMLA, D., ABASTADO, P., "Vésale, Paré et Paracelse: trois figures médicales majeures de la Renaissance", in La lettre du cardiologue - Risque Cardiovasculaire, n.. 428, outubro de 2009 , p. 35.

CLASTRES, Pierre. Le grand parler: Mythes et chants sacrés des Indiens Guarani, Paris, Seuil, 1974, 14-15p.

Dicionário PRIBERAM, https://dicionario.priberam.org/. Acesso em 01 de novembro de 2018.

FOUCAULT, Michel. L’Archéologie du savoir, Paris, Gallimard, 1969, 175p.

Les mots et les choses: une archéologie des sciences humaines, Paris, Gallimard, 1966, 400p.

JUIGNET, Patrick. Michel Foucault et le concept d'épistème". In: Philosophie Science et société (en ligne). 2015. https://philososciences.com/philosophie-generale/laphilosophie-et-sa-critique/10-michel-foucault-episteme (/philosophie-et-societe/29philosophie-generale/-la-philosophie-et-sa-critique/10-michel-foucault-episteme). Acesso em $01 / 11 / 2018$

KRISTEVA, Julia, Le génie féminin 1. Hannah Arendt, Paris, Fayard 1999, p. 9.

LEITE, Marcos Vinícius. “A estrutura da linguagem em Walter Benjamin”. Revista Ética e Filosofia Política. No 12. Volume 1. Abril de 2010, p. 11-23. 
RAULET, Gérard. “L'atelier du traducteur. Benjamin et les Tableaux parisiens”, Revue italienne d'études françaises [online], 4, 2014, http://journals.openedition.org/ rief/656. Acesso em 30 de agosto de 2018.

Richard Aline, Le Meur Hélène, Les grandes controverses scientifiques, Paris, Dunod, 2014, pp. 2-5.

ROSCOE-BESSA, Cristiane. "O conceito de linguagem em Walter Benjamin e sua relação com a tradução”. Traduzires. Vol. 4. 2013. p. 29-39.

Autor. “Entrevista com o Prof. Dr. Emérito Aryon Dall'Igna Rodrigues por Autor, Traduzires, n. 2, Dezembro de 2012, p. 127.

. "Processos e experiências: pensando a tradução". caleidoscópio: linguagem e tradução, Vol, 2, n. 1, Junho de 2018, p. 1-14. 